\title{
MANAJEMEN PENDIDIKAN BERASRAMA DI STAI AS-SUNNAH TANJUNG MORAWA DELI SERDANG
}

\author{
Bahrul Ulum ${ }^{1}$, Ficki Pali Paredede ${ }^{2}$,Dr. Candra Wijaya, M.Pd. ${ }^{3}$
}

bahrul.ulum1507@gmail.com

\begin{abstract}
This study aims to identify and analyze planning, resource management, implementation and evaluation of management of boarding education in Stai As-Sunnah Tanjung Morawa Deli Serdang.

This study uses a qualitative method. The process of collecting data uses observation, interview and document study techniques. Informant chairman of Stai As-Sunnah, puket 3 and head of boarding care ... In analyzing the data the researcher used qualitative analysis with steps of data exposure, data reduction and conclusion drawing.

The results of this study indicate that; 1) the planning process is carried out by deliberation followed by the chairperson of Stai As-Sunnah, puket 3 and the head of boarding and subordinates 2) the process of organizing resources with the division of tasks according to their expertise including the student executive body, preparation of daily activity schedules, monthly activity schedules and schedules annual activities 3 ) the process of implementing boarding education includes the implementation of a series of activities carried out by the Head of care and its staff in providing motivation, direction and guidance as well as student executive bodies based on the implementation of STAI As-Sunnah learning and activities. monthly reports and supervision of puket 3 to the dormitory when the activities are taking place.
\end{abstract}

Keywords: Management, Boarding Education

\begin{abstract}
Abstrak Penelitian ini bertujuan untuk mengetahui dan menganalisis perencanaan, pengaturan sumberdaya, pelaksanaan dan evaluasi manajemen pendidikan berasrama di Stai As-Sunnah Tanjung Morawa Deli Serdang. Penelitian ini menggunakan metode kualitatif. Proses pengumpulan data menggunakan teknik observasi, wawancara dan studi dokumen. Informan ketua Stai As-Sunnah, puket 3 dan kepala pengasuhan asrama..Dalam menganalisis data peneliti menggunakan analisis kualitatif dengan langkah-langkah pemaparan data, reduksi data dan penarikan kesimpulan. Hasil penelitian ini menunjukan bahwa; 1) proses perencanaan dilakukan dengan musyawarah diikuti oleh ketua Stai AsSunnah, puket 3 dan kepala pengasuhan asrama serta bawahannya 2) proses pengorganisasian sumberdaya dengan pembagian tugas sesuai keahlian yang dimiliki meliputi badan eksekutif mahasiswa, penyusunan jadwal kegiatan harian, jadwal kegiatan bulanan dan jadwal kegiatan tahunan 3) proses pelaksanaan pendidikan berasrama meliputi pelaksanaan rangkaian kegiatan yang dilakukan Kepala pengasuhan serta jajarannya dalam memberikan motivasi, arahan dan bimbingan serta badan eksekutif mahasiswa berdasarkan rencana pelaksanaan pembelajaran dan kegiatan STAI As-Sunnah 4) proses evaluasi meliputi pemeriksaan dokumen rencana pelaksanaan kegiatan, laporan bulanan serta, supervisi puket 3 ke asrama ketika pelaksanaan kegiatan sedang berlangsung.
\end{abstract}

Kata kunci: Manajemen, Pendidikan Berasrama

\section{PENDAHULUAN}

Pendidikan dalam pandangan umum seperti yang sudah diungkapkan sangat memiliki peranan yang besar dalam kehidupan bermasyarakat, berbangsa dan bernegara. Menurut Undang-Undang Sistem Pendidikan 
Nasional No.20/2003 (UU Sisdiknas) pasal 1 ayat (1): "Pendidikan adalah usaha sadar dan terencana untuk mewujudkan suasana belajar dan proses pembelajaran agar peserta didik secara aktif mengembangkan potensi dirinya untuk memiliki kekuatan spiritual keagamaan, pengendalian diri, kepribadian, kecerdasan diri, akhlak mulia, serta keterampilan yang diperlukan dirinya, masyarakat, bangsa dan negara".

Pendidikan merupakan kata kunci setiap manusia untuk memudahkan mendapatkan ilmu pengetahuan dan teknologi. Hanya dengan pendidikan yang efektif ilmu akan didapat dan diserap dengan baik. Tak heran bila kini pemerintah mewajibkan program belajar 9 tahun agar masyarakat menjadi pandai dan beradab.Pendidikan juga merupakan metode pendekatan yang sesuai dengan fitrah manusia yang memiliki fase tahapan dalam pertumbuhan.

Demikian besarnya perhatian terhadap pentingnya pendidikan ini dalam pandangan Islam bahkan dinyatakan bahwa pendidikan menjadi hak dan kewajiban azazi, setiap individu wajib dan harus diberi peluang untuk mengikuti dan mendapatkan pendidikan. Karena itu melalui pendidikanlah manusia dapat meningkatkan kualitas keimanan dan keilmuannya yang menjadi modal dasar untuk meningkatkan taraf hidup berbahagia di dunia dan bahagia di akhirat.(Fachruddin Azmi, 2016:80)

Pendidikan Islam dikenal dan diyakini oleh penganut agama Islam sebagai suatu kegiatan pendidikan yang bersumber dari ajaran Islam dengan nilai-nilai universal yang terkandung di dalamnya yang senantiasa mempertimbangkan pengembangan fitrah manusia atau potensipotensi yang dimiliki manusia selaku makhluk. Untuk mencapai tujuan tersebut, maka diperlukan adanya suatu program yang terencana dan dapat menghantar proses pendidikan sampai pada tujuan yang diinginkan.

Perkembangan teknologi dan ilmu pengetahuan pada saat ini mempengaruhi cara pandang masyarakat dan orang tua siswa dalam memberikan aprisiasi terhadap proses yang dijalankan oleh lembaga pendidikan secara cepat dan akurat, sejak dari sistem, layanan, metode pembelajaran serta dampak hiden kurikulum yang muncul dalam perilaku siswa. Berbagai layanan pendidikan dan motede pendekatan yang efektif, secara terencana dan terus-menerus diusahakan oleh para guru, pembina dan seluruh element yang terlibat dalam peroses pendidikan dan pengajaran, agar menghasilkan output siswa yang berprestasi sesuai dengan visi lembaga yang dicanangkan.

Perubahan lingkungan sosial dan keadaan ekonomi serta cara pandang religiusitas masyarakat memberikan konsekwensi logis atas kehadiran sekolah berasrama zaman kini. Dari ketiga faktor tersebut, sistem pendidikan berasrama seolah menemukan pasarnya.Dari segi sosial, sistem pendidikan berasrama mengisolasi anak didik dari lingkungan sosial yang heterogen yang cenderung buruk.Di lingkungan sekolah dan asrama dikonstruksi suatu lingkungan sosial yang relatif homogen 
yakni teman sebaya dan para guru pembimbing.Homogen dalam tujuan yakni menuntut ilmu sebagai sarana mengejar citacita.Dari segi ekonomi, pendidikan berasrama memberikan layanan yang paripurna sehingga menuntut biaya yang cukup tinggi. Oleh karena itu anak didik akan benar-benar terlayani dengan baik melalui berbagai layanan dan fasilitas. Dari segi semangat religiusitas.pendidikan berasrama menjanjikan pendidikan yang seimbang antara kebutuhan jasmani dan ruhani, intelektual dan spiritual serta sifat kemadirian dan jiwa kepemimpinan.

Nampaknya, konsep pendidikan berasrama menjadi alternatif pilihan sebagai model dari pengembangan pesantren yang akan datang. Pemerintah diharapkan semakin serius dalam mendukung dan mengembangkan konsep pendidikan seperti ini.Sehingga, pesantren menjadi lembaga pendidikan yang maju dan bersaing dalam mengembangkan ilmu pengetahuan dan keterampilan yang berbasis pada nilai-nilai spiritual.

Sutrisno Muslimin menyebutkan dalam artikelnya bahwa ketika dipertengahan tahun 1990 an masyarakat Indonesia mulai gelisah dengan kondisi kualitas generasi bangsa yang cenderung terdikotomi secara ekstrim-yang pesantren terlalu keagama dan yang sekolah umum terlalu keduniawian - ada upaya untuk mengawinkan pendidikan umum dan pesantren dengan melahirkan term baru yang disebut boarding school atau internat yang bertujuan untuk melaksanakan pendidikan yang lebih komprehensif-holistik, ilmu dunia(umum) dapat capai dan ilmu agama juga dikuasai. Maka sejak itu mulai munculah banyak sekolah boarding yang didirikan yaitu SMA Madania di Parung Bogor, SMA Al-Azhar di Lippo = Cikarang, SMA Insan Cendekia di Serpong, SMA Dwiwarna di Parung Bogor, SMP dan SMA Al-Kautsar di Sukabumi, SMA Salman Al-Farisi, SMA IIBS di Lippo Cikarang. (Sutrisno Musimin:2)

Salah satu perguruan tinggi yang menerapkan pendidikan berasrama yaitu Sekolah Tinggi Agama Islam As-Sunnah Tanjung Morawa Deli Serdang, sebelumnya dinamakana Ma'had Aly As-Sunnah.Seiring dengan berjalannya waktu, Ma'had Aly Assunnah telah banyak mencetak lulusan yang mempunyai kemampuan berbahasa Arab dan ilmu-ilmu Islam yang bagus sebanyak 8 angkatan. Sebagian besar lulusan melanjutkan pendidikannya ke jenjang yang lebih tinggi, baik di luar negeri, seperti Arab Saudi, dan di dalam negeri, seperti: LIPIA Jakarta, IAIN Medan dan lain-lain. Demikian halnya, banyak pula yang terjun ke medan dakwah dan pendidikan Islam untuk mengabdikan ilmunya bagi kepentingan agama Islam. Melihat kebutuhan akan sarjana-sarjana Islam yang begitu tinggi (terutama di bidang pendidikan dan dakwah), dan sebagai bentuk kepedulian pengelola akan dakwah Islam serta komitmen pengelola untuk meningkatkan kemampuan para mahasiswa dengan ilmu agama dan bahasa Arab yang lebih tinggi, sebagai modal utama untuk menjawab kebutuhan masyarakat sekaligus sebagai sarana dakwah Islamiyyah 
yang relevan dengan dinamika zaman, maka Ma'had 'Aly As-sunnah program D III ditingkatkan menjadi STAI As-sunnah program S1 masa studi 4 tahun. Alhamdulillah, berkat kerjasama, dukungan dan perjuangan seluruh sivitas akademika, tentunya setelah prosedur demi prosedur dipenuhi dengan baik, akhirnya harapan Ma'had 'Ali As-Sunnah tersebut dapat terwujud. Pada bulan Februari tahun 2012 kemarin Ma'had 'Ali As-Sunnah resmi menjadi STAI

Fasilitas diberikan (Berdasarkan sistem dan prosedur penerimaan) diantaranya: bebas uang kuliah, spp dan lainnya, buku referensi utama dibagikan cuma-cuma, perpustakaan yang lengkap dan nyaman dilengkapi dengan fasilitas internet, asrama (tempat tidur, kasur, bantal, seprei, lemari) gratis, musholla dan kantin, sarana olah raga (bola kaki, badminton, volley, takraw, dan karate), makan (disubsidi yayasan bagi yang memenuhi syarat), lab komputer, fasilitas mesin jahit,dll

Disamping fasilitas yang diberikan juga, Stai As-Sunnah memberikan Beasiswa Prestasi dengan berbagai katergori, yaitu Mumtaz Murtafi' (cumlaude) : Rp. 500.000,- Mumtaz (istimewa) : Rp.300.000,- Jayyid Jiddan ( baik sekali ) Rp. 150.000,-. Hal yang lebih menarik lagi dari keistimewaan nya adalah Tenaga Pengajar dari dalam dan luar negeri, Pembelajaran dasar-dasar Bahasa Arab untuk pemula selama setahun, Penggunaan Bahasa Arab sebagai pengantar dalam belajar dan kajian-kajian ilmiah, Setiap kelas dilengkapi dengan proyektor sebagai penunjang pembelajaran, Seminar Internasional diadakan dua kali dalam setahun dengan pemateri dari Arab Saudi, Beragam kegiatan Ekstrakulikuler yang mengembangkan minat dan bakat mahasiswa. Sistem pembelajaran selama 24 jam di Pendidikan berasrama dengan lingkungan yang unik dan memberikan dorongan kepada mahasiswa untuk tidak hanya aktif di kelas saja, tetapi juga aktif di luar kelas dengan berpartisipasi dalam kegiatan ekstrakurikuler maupun kegiatan lain

Terkait dengan latar belakang di atas sepantasnya mendapat perhatian dengan munculnya berbagai sekolah yang bervariatif dalam menggunakan metodenya termasuk metode pendidikan berasrama. Pada penelitian ini akan di fokuskan manajemen pendidikan berasrama di Sekolah Tinggi Agama Islam AsSunnah Tanjung Morawa Deli Serdang.

\section{HASIL \& PEMBAHASAN}

1) Kegiatan-Kegiatanektrakulikuler STAI As-Sunnah.

Belajar formal di kelas merupakan kegiatan program pendidikan utama di Sekolah Tinggi Agama Islam program S1 masa studi delapan semester atau 4 tahun. Dalam bidang akademik, pendidikan yang diselenggarakan melalui perkuliahan dengan sistem pembelajaran yang tidak hanya berorientasi pada penguasaan ilmu pengetahuan saja, tetapi sampai pada tataran penguatan sikap dan perilaku dalam 
praktek.Hal ini diwujudkan dalam kebijakan STAI As-Sunnah yang mewajibkan seluruh mahasiswa untuk mengikuti Kuliah Kerja Lapangan (KKL) dan Praktek Pengalaman Lapangan (PPL) yang diselenggarakan oleh setiap program studi.

Sebagai upaya peningkatan prestasi mahasiswa dalam bidang akademik dan nonakademik di STAI As-Sunnah, maka diselenggarakan kegiatan-kegiatan kemahasiswaan melalui program bidang akademik dan kemahasiswaan.Pusat Pengembangan Minat dan Bakat (PMBT) memiliki tujuan utama untuk mengembangkan potensi dasar mahasiswa baik dalam hal hard skills maupun soft skills.

Upaya memberikan peluang yang seluas-luasnya kepada mahasiswa untuk dapat mengaktualisasikan dirinya secara utuh tercermin dalam:

a) Mahasiswa diberikan kebebasan akademik dalam rangka pengembangan IPTEKS, dan kebebasan dalam menata organisasi kemahasiswaan.

b) Pembina kemahasiswaan senantiasa menunjukkan sikap mengayomi dan penuh perhatian.

c) Mendorong mahasiswa untuk senantiasa peka terhadap permasalahan yang berkembang di tengah-tengah masyarakat, dan diberi kesempatan untuk turut serta dalam mencari pemecahannya.

Dengan demikian kegiatan kemahasiswaan di STAI As-Sunnah diarahkan agar dapat menjadi kegiatan yang terintegrasi secara berkesinambungan dengan kegiatan akademik, sehingga mahasiswa dapat mengembangkan minat, bakat dan potensi dirinya secara maksimal yang pada gilirannya akan menghasilkan prestasi yang membanggakan. Wadah yang efektif untuk mengarahkan dan mengembangkan potensi mahasiswa adalah organisasi kemahasiswaan yang sah. Penyelenggaraan organisasi kemahasiswaan di STAI As-Sunnah diatur dalam Surat Keputusan Ketua STAI As-Sunnah Nomor: 017/K/C/X.1433-IX.2012. Di STAI AsSunnah organisasi kemahasiswan terdiri dari:

a) Tingkat kampus, meliputi:

1. Badan Eksekutif Mahasiswa (BEM)

2. Unit Kegiatan Mahasiswa (UKM)

b) Tingkat Program Studi adalah Himpunan Mahasiswa Program Studi (HMPS).

Melalui Unit Kegiatan Mahasiswa (UKM), mahasiswa dapat meningkatkan penalaran dan keilmuannya, menyalurkan minat dan kegemarannya, meningkatkankemampuan berwirausaha, serta ketaqwaannya kepada Allah Ta'ala., 
Guna memudahkan dalam pelaksanaan fasilitasi dan pendampingan pengembangan potensi mahasiswa, sesuai, kegiatan kemahasiswaan di STAI As-Sunnah dikelompokkan dalam 4 (empat) bidang kegiatan, yaitu:

a) Bidang Penalaran. merupakan kegiatan ilmiah di luar kegiatan akademik, yang diselenggarakan secara rutin sekali sampai dua kali dalam satu tahunnya yang dibimbing Ulama' dan Doktor dari Timur Tengah, seperti: seminar, pelatihan, Program Kreativitas Mahasiswa (PKM).

b) Bidang Minat, Bakat, dan Kegemaran. Bidang ini mencakup berbagi kegiatan, yaitu: Pengobatan ala Nabi (Tibbun Nabawi), olah raga, kesenian, bulletin mahasiswa (An-Nur), bela diri, komunitas ilmiah, komunitas khat, komunitas komputer, komunitas menjahit, dll.

c) Bidang Organisasi. Bidang ini mencakup organisasi yang sifatnya kepanitiaan, kelembagaan, intra dan ekstra kampus.

d) Bidang Kesejahteraan dan Bakti Sosial. Bidang ini diwujudkan dalam kerohanian, kesehatan, asuransi, dan pusat bisnis mahasiswa. Kegiatan bakti sosial meliputi baik yang terprogram maupun yang insidental yang dilaksanakan di dalam dan di luar kampus. Untuk mewadahi kegiatankegiatan tersebut, di STAI As-Sunnah dibentuk 6 UKM.

1. UKM Olah Raga

2. UKM Matara

3. UKM Peduli Bencana

4. Buletin An-Nuur

5. UKM Tibbun Nabawi

6. UKM Ilmiah

Berdasarkan program kerja tahunan, mahasiswa akan didorong untuk ikut berpartisipasi dalam pelaksanaannya sesuai dengan bidang masing-masing. Beberapa program yang berkaitan dengan peningkatan prestasi mahasiswa di bidang non-akademik yang secara rutin dilaksanakan setiap tahun, antara lain adalah:

1. Pelatihan Dasar Kepemimpinan (LDK).

2. Pembinaan olah raga dan seni secara rutin.

3. Pengiriman delegasi lomba hafalan Al-qur'an dan Hadist Pangeran Sultan bin Abdul Aziz Su'ud tingkat nasional dan internasional.

4. Seminar Internasional.

Adapun kebebasan akademik di STAI As-Sunnah pada tingkat mahasiswa diwujudkan melalui: 
1. Mahasiswa diberikan kebebasan berdiskusi di kelas atau mengajukan pertanyaan dan pendapat pada saat proses pembelajaran di kelas bersama dosen.

2. Mahasiswa diberikan kebebasan untuk membentuk Lajnah Ilmiyah. Lajnah Ilmiyah ini memiliki program pengembangan ilmu agama di luar kelas. Diantaranya: bedah buku dengan mengundang nara sumber dari luar STAI As-Sunnah, dan mengadakan kajian ilmiah setelah shalat maghrib denganpemateri dari dosen STAI AsSunnah dengan mengkaji kitab-kitab agamaIslam seperti kitab al-Ushul astTsalatsah, Kasyfu asy-Syubuhat dal lain-lain.

3. Mahasiswa diberikan kebebasan untuk melakukan kegiatan pengabdian kepada masyarakat yang difasilitasi oleh STAI As-Sunnah dan Yayasan Ar Risalah Alkhairiyah seperti melakukan kegiatan ceramah agama di Sekolah/Masjid dan khutbah Jum'at. Mahasiswa diberikan kebebasan untuk menerbitkan buletin yang diisi dengan tulisan dan pemikiran mahasiswa. Buletin mahasiswa tersebut bernama buletin "An-Nuur", terbit setiap 2 minggu sekali. Buletin ini juga Pengasuhan Minat dan Bakat, serta memiliki akun khusus di Facebook dilakukan monitoring dan evaluasi secara

untuk mempublikasikan tulisan-tulisan tersebut. Selain diisi dengan tulisantulisan mahasiswa, akun ini juga berfungsi untuk mempublikasikan video ceramah singkat yang dibuat oleh mahasiswa.

Di samping itu, STAI As-Sunnah juga memfasilitasi program dan kegiatan di dalam dan di luar proses pembelajaran, yang dilaksanakan baik di dalam maupun di luar kelas, untuk menciptakan suasana akademik yang kondusif. Di antara kegiatan tersebut adalah sebagai berikut:

1) Kegiatan ekstrakurikuler yang terintegrasi dengan program kepesantrenan.

2) Kegiatan pelatihan, seminar, lokakarya dan workshop.

3) Kegiatan diskusi terbuka.

4) Kegiatan debat ilmiah.

5) Kegiatan safari dakwah.

6) dan lain sebagainya.

Pelaksanaan program dan kegiatan ekstrakurikuler yang mendukung suasana akademik bagi mahasiswa secara detail tercantum dalam pedoman kegiatan ekstrakurikuler di lingkungan STAI AsSunnah. Selain itu, kegiatan-kegiatan tersebut dikoordinir langsung oleh Wakil Ketua III bidang kemahasiswaan melalui 
periodik untuk terus dilakukan perbaikan.

Penilaian terhadap pelaksanaan peningkatan suasana akademik dilakukan secara berkala oleh Lembaga Penjaminan Mutu STAI AsSunnah berkoordinasi dengan program studi, dengan metode menyebar kuesioner kepada mahasiswa tentang pelayanan dosen kepada mahasiswa baik akademik maupun non akademik, keterbukaan dosen dalam proses evaluasi pembelajaran, keterbukaan dosen dalam menerima kritik dari mahasiswa. Hasil evaluasi akan ditindaklanjuti sebagai bahan perencanaan/program-program kerja tahunan.

1. Perencanaan Pelaksanaan Pendidikan Berasrama

Dalam pelaksanaan kegiatan manajemen di STAI As-Sunnah diawali dengan tahapan perencanaan. Perencanaan tersebut meliputi perencanaan dalam penetapan visi, misi, tujuan, strategi pencapaian, perencanaan anggaran, perencanaan SDM, perencanaan kegiatan Tridarma Perguruan Tinggi, perencanaan penetapan renstra dan renop yang dilakukan oleh Ketua STAI dan Senat dengan persetujuan Yayasan. Renop atau Rencana Operasional dibuat dua bulan sebelum berakhir tahun akademik yang berjalan untuk satu tahun akademik yang baru.Renstra atau Rencana Strategis STAI As-Sunnah dibuat untuk masa 5 tahun. STAI As Sunnah sudah memiliki 2 Renstra, yaitu Renstra 2012-2016 dan Renstra 2016-2020.

Proses perencanaan pada bidang asrama dilakukan dengan musyawarah diikuti oleh ketua Stai As-Sunnah, puket 3 dan kepala pengasuhan asrama serta bawahannya dengan diterbitkannya program tahunan.

2. Pengorganisasian pelaksanaan pendidikan berasrama

Untuk pelaksanaan operasional manajemen STAI As-Sunnah dibentuk struktur organisasi yang disesuaikan dengan kebutuhan tugas yang akan dilaksanakan. Organisasi STAI AsSunnah sesuai dengan kebutuhan kerjanya dibagi dalam beberapa wilayah kerja yaitu Bidang Akademik, Bidang Administrasi, Bidang Kemahasiswaan, Bidang Sarana Prasarana, Bidang Penjaminan Mutu dan Bidang Humas, Bidang Asrama dan Pusat Informasi. Setiap bagian dalam pelaksanaan tugasnya diatur dalam job deskripsi sebagaimana yang ditetapkan dalam Pedoman Mutu STAI As-Sunnah, Tupoksi Jabatan Struktural STAI As-Sunnah (SK Ketua STAI no. 
454/K/A/XI.1438-VIII.2017), Standar Operasional Prosedur (SK Ketua STAI no. $374 / \mathrm{K} / \mathrm{C} / \mathrm{IX} / 2016) \quad$ setiap pekerjaannya.

Terkhusus bidang asrama, struktur organisasinya dibawah wakil ketua III bidang bidang kemahasiswaan dan bertanggungjawab kepada Ketua.

3. Pelaksanaan Pendidikan Berasrama

Proses pelaksanaan pendidikan berasrama meliputi pelaksanaan pembelajaran yang dilakukan Kepala pengasuhan serta jajarannya berdasarkan rencana pelaksanaan pembelajaran dan kegiatan STAI AsSunnah dalam memberikan motivasi, arahan dan bimbingan dan pembuatan rencana pelaksanaan pembelajaran. Dalam tatanan praktikalnya, badan eksekutif mahasiswa dengan tugas dan kewenangannya difungsikan dengan maksimal terhadap program-program ektrakulikuler.BEM ini memiliki sturktural organisasinya serta tugas dan fungsinya masing-masing.

4. Evaluasi Pelaksanaan Pendidikan Berasrama

Ketua STAI As-Sunnah sebagai penanggungjawab utama atas terselenggaranya kegiatan tridarma perguruan tinggi di STAI As-Sunnah melakukan pengawasan secara aktif dan berkesinambungan.Secara umum pengawasan terhadap pelaksanaan tridarma perguruan tinggi di STAI As-Sunnah dilakukan oleh Ketua STAI As-Sunnah dan Yayasan Ar-Risalah sebagaimana yang ditetapkan pada Statuta STAI AsSunnah.Untuk efektifnya pelaksanaan pengawasan, maka Ketua STAI mendelegasikan wewenangnya kepada seluruh Wakil Ketua sesuai dengan bidang masing-masing. Rincian dari pendelegasian wewenang itu adalah sebagai berikut:

a. Wakil Ketua I melakukan pengawasan terhadap penyelenggaraan bidang akademik yang meliputi administrasi akademik dan proses belajar mengajar dan bertanggungjawab kepada Ketua.

b. Wakil Ketua II melakukan pengawasan pada bidang administrasi umum dan keuangan dan bertanggungjawab kepada Ketua.

c. Wakil Ketua III melakukan pengawasan pada bidang kemahasiswaan dan bertanggungjawab kepada Ketua.

d. Wakil Ketua IV melakukan pengawasan pada bidang sarana prasarana dan bertanggungjawab kepada Ketua.

e. Pengawasan bidang non akademik yang berkenaan Fungsionaris dan 
karyawan dilaksanakan oleh Yayasan Ar-Risalah.

Bila cermati dengan rincian delegasi diatas maka evaluasi asrama dari kepala pengasuhan di tembuskan ke wakil ketua III untuk selanjutnya diteruskan ke ketua STAI.

\section{SIMPULAN}

Berdasarkan hasil penelitian dan pembahasan yang penulis lakukan, maka dapat disimpulkan sebagai berikut:

1. Proses perencanaan pendidikan berasrama Stai As-Sunnah Tanjung Morawa DeliSerdang dilakukan melalui rapat dan musyawarah yang dilakukan oleh ketua STAI, wakil ketua III dan kepala pengasuhan serta jajarannya.

2. Proses pengorganisasian atau pengaturan sumberdaya pendidikan berasrama Stai As-Sunnah Tanjung Morawa DeliSerdang meliputi pembagian tugas bimbingan dan penyuluhan kepada semua personil sekolah sesuai dengan keahliannya masing-masing dan tugas pelaksanaan berbagai kegiatan kepada badan eksekutif mahasiswa, serta penyusunan jadwal harian, mingguan, bulanan dan tahunan.
3. Proses pelaksanaan pendidikan berasrama Stai As-Sunnah Tanjung Morawa DeliSerdang, meliputi pelaksanaan kegiatan berdasarkan rencana pelaksanaan kegiatan yang telah dibuat ketua STAI, Wakli Ketua III dan kepala pengasuhan dan dilaksanakan oleh badan eksekutif mahasiswa

4. Proses evaluasi pendidikan berasrama Stai As-Sunnah Tanjung Morawa DeliSerdang meliputi pemeriksaan dokumen kegiatankegiatan yang telah direncanakan dalam bentuk laporan bulanan serta tahunan dan supervisi ketua STAI dan wakil ketua III ke asrama secara langsung ketika pelaksanaan berlangsungnya kegiatan.

\section{DAFTAR RUJUKAN}

Fachruddin Azmi. (2016). Kebijakan Pendidikan Islam; memperdayakan peradaban Medan:Manhaji

Abubakar dan Taufani C. Kurniatun.(2005). Manajemen Pendidikan. Bandung: Alfabeta

Daryanto. (2013). Pengantar Kewirausahaan, Jakarta: prestasi Pustakaraya

Departemen Pendidikan Nasional. (2008). amus Besar Bahasa Indonesia, Pusat bahasa, Jakarta:Gramedia 
Ahmad, Farid.(2011). Pendidikan Berbasis Metode Ahlu Sunnah Wal Jama'ah. Surabaya: Pustaka Elba

Undang-Undang Republik Indonesia No. 20 Tahun 2003 tentang Sistem Pendidikan Nasional. Bandung: Citra Umbara

Haidar Putra Daulay (2012). Sejarah Pertumbuhan dan Pembaruan Pendidikan Islam Di Indonesia, Jakarta: Kecana Prenada Media Group

T. Hani Handoko. (1999). Manajemen Edisi 2. Yogyakarta: BPFE 